REVIEW

\title{
Background exposure to PCDDs/PCDFs/PCBs and its potential health effects : a review of epidemiologic studies
}

\author{
Kokichi Arisawa, Hideo Takeda, and Hiroaki Mikasa \\ Department of Preventive Medicine, Institute of Health Biosciences, The University of Tokushima Graduate \\ School, Tokushima, Japan
}

\begin{abstract}
Here we review epidemiologic studies dealing with the dietary intake and the body burden of polychlorinated dibenzo-p-dioxins (PCDDs)/polychlorinated dibenzo-furans (PCDFs)/ polychlorinated biphenyls (PCBs) in the general population, and potential adverse health effects of these substances, especially on the risk of diabetes mellitus and endometriosis, and on thyroid function and the neurodevelopment of infants. The mean or median intake of dioxin-related compounds among the general populations of various countries is lower than the maximum tolerable daily intake (TDI) set by the WHO in 1998 (4pg TEQ/kg/day). However, there have been few reports on the distribution of intake and the proportion of subjects whose exposure levels exceed the maximum TDI. At present, it remains unclear whether background exposure to dioxin-related compounds is associated with increased risk of diabetes (because of lack of longitudinal studies), endometriosis (because of lack of studies with sufficient statistical power), or altered thyroid function (because of inconsistent results on humans). Consistent results have been reported for the association between exposure to background levels of PCBs/dioxins, especially trans-placental PCBs, and defective neurodevelopment of infants in the U.S. and Europe. Thus, efforts should be made to further decrease the body burden among women of reproductive age by reducing the release of PCDDs/PCDFs/PCBs into the environment. J. Med. Invest. 52 : 10-21, February, 2005
\end{abstract}

Keywords : dioxin-related compounds, diabetes, thyroid function, endometriosis, neurodevelopment

\section{INTRODUCTION}

Polychlorinated dibenzo-p-dioxins (PCDDs) and polychlorinated dibenzo-furans (PCDFs) are a group of toxic chemical substances that are produced unintentionally during thermal and industrial processes, such as incineration of wastes, production of organic chlorinated herbicides and bleaching of papers (1). Humans are exposed to low levels of PCDDs/PCDFs through food, water, the atmosphere and soil even in the absence of occupational or accidental exposure. Because of their lipophilic and persistent nature,

Received for publication November 15, 2004 ; accepted December 27, 2004.

Address correspondence and reprint requests to Kokichi Arisawa, MD, MSc, PhD, Department of Preventive Medicine, Institute of Health Biosciences, The University of Tokushima Graduate School, Kuramotocho, Tokushima 770-8503, Japan and Fax : +81-886-33-7074.
PCDDs/PCDFs are accumulated in various organs of wild animals and the human body, in adipose tissue and liver in particular, through the food chain. The toxic and biochemical responses induced by PCDDs/ PCDFs include carcinogenicity, endocrine, reproductive, neurobehavioral and immune effects, and induction of drug metabolizing enzymes such as CYP1A1(1). PCDDs/PCDFs are considered to exert their toxic effects through a common mechanism mediated through the aryl hydrocarbon receptor (AhR) (binding to AhR, formation of heterodimers with AhR nuclear translocator [ARNT] in the nucleus and binding to the xenobiotic response element and regulation of the expression of various genes). The strength of the toxicity of PCDDs/PCDFs is expressed relative to that of 2,3,7,8-tetrachlorodibenzo-p-dioxin (TCDD) using the Toxic Equivalency Factor (TEF, with the 
TEF of 2,3,7,8-TCDD=1) (2,3). Polychlorinated biphenyls (PCBs) are another group of persistent anthropogenic organic pollutants. Although their production and use in open systems was banned in the early 1970 's, PCBs are ubiquitously detected in various tissues of wildlife and the human body. Some forms of PCBs with coplanar structures (coplanar-non-ortho and mono-ortho PCBs [co-PCBs]) have toxicities similar to that of 2,3,7,8-TCDD. So far, TEFs have been estimated for 7 PCDDs, 10 PCDFs and 12 co-PCBs.

In 1998, the WHO set the tolerable daily intake (TDI) of PCDDs/PCDFs/co-PCBs (dioxins or dioxinrelated compounds) as 1-4 pg Toxicity Equivalents (TEQ) $/ \mathrm{kg} /$ day (4). The TDI is defined as the maximum daily intake of an undesirable toxic substance that would not lead to the development of adverse health effects with lifetime exposure. The TDI of dioxins was calculated on the basis of the following equation, using the lowest body burden of animals at which adverse developmental and/or reproductive effects have been observed $(5,6)$, the biological half-life ( 7.5 years) and absorption rate $(50 \%)$ of dioxins, and the safety factor of 10(4).

Intake (ng/kg/day)=Body Burden $(\mathrm{ng} / \mathrm{kg}) \times(\mathrm{ln}$ [2]/biological half-life)/(absorption rate)

At present, except in special populations with heavy exposure, the mean or median intake levels among the general populations of various countries are considered to be below the TDI, as discussed later. However, it is of concern to researchers whether there are subtle adverse health effects of PCDDs/PCDFs/PCBs among human populations even at background exposure levels. Here we review epidemiologic studies dealing with the dietary intake and the body burden of dioxinrelated compounds and their potential adverse health effects, especially increased risk of diabetes mellitus or endometriosis, and alterations of thyroid function or the neurodevelopment of infants, at the current background exposure levels. Effects on cancer risk were excluded because the association may not be strong (standardized mortality ratio for all cancers combined=1.6) even among a population whose exposure level is two to three orders of magnitude higher than the general population (7).

\section{Dietary intake of PCDDs/PCDFs/co-PCBs}

Evaluation of dietary intake is crucial in the exposure assessment of dioxin-related compounds because more than $90 \%$ of exposure occurs via foods. Two methods have been used to estimate the dietary intake among populations, i.e., the market basket method and the duplicate portion analysis. In the former method, the dietary intake is estimated based on the dioxin content in various food samples (usually measured by high resolution gas chromatography/mass spectrometry $[\mathrm{GC} / \mathrm{MS}]$ ), and multiplied by the average or individual consumption of corresponding foods, which is derived from nutrition surveys. In the latter method, the respondents of the survey prepare two sets of identical meals, and one of them is directly analyzed for dioxin content.

Table 1 presents the mean or median dietary intake of PCDDs/PCDFs (8-19) and PCDDs/PCDFs/co-PCBs $(14,16,17,20-26)$, expressed as pg TEQ $/ \mathrm{kg} /$ day or pg TEQ/day, among adults, children and breast-fed infants in various countries. All studies but two (17, 25) were based on the market basket method. It should be pointed out that some researchers did not analyze all 29 congeners/isomers of PCDDs/PCDFs/co-PCBs for which TEF have been assigned. In addition, different (Nordic, International, WHO 1994, 1998) TEFs and body weights were used to calculate dioxin intake. Despite these methodological differences, except in one Spanish study with high PCDDs/PCDFs intake (19), the mean or median intake of dioxins among adults of most countries ranged from 0.33 to $3.57 \mathrm{pg}$ $\mathrm{TEQ} / \mathrm{kg} /$ day, which is lower than the maximum TDI set by the WHO in 1998 (4 pg TEQ/kg/day) (4).

It has been reported that in most Western countries, dioxin intake originated from various foods, such as meat, meat products, milk, dairy products and fish, whereas in Japan, Finland and Norway, the dioxin intake, especially co-PCBs, was predominantly derived from fish and fish products $(16,23)$. Although Japanese people consume large amounts of fish, the dietary intake of dioxins seems not to be higher than in Western countries (Table 1).

One problem that should be addressed is that the distribution (variance or standard deviation) of dioxin intake remains unknown, or reflected only that of the short-term intake in most previous reports. Usually, the short-term intake exhibits larger variance than the long-term intake because it contains not only betweensubject variation but also within-subject variation (27). Therefore, use of short-term intake may lead to overestimation of the proportion of subjects whose dioxin exposure is higher than the TDI. In one study (24), however, the $95^{\text {th }}$ percentile of the dioxin intake was estimated at $2.0 \mathrm{pg}$ TEQ $/ \mathrm{kg} /$ day by using repeated measurements on the same individuals and statistically accounting for the within-person variance. Such an approach may be useful for clarifying the distribution 
Table 1. Estimated mean dietary intake of dioxin-related compounds in adults, children and breast-fed babies in various countries

\begin{tabular}{|c|c|c|c|c|}
\hline Country & $\mathrm{pg}$ TEQ/kg/day & pg TEQ/day & Year of survey & References \\
\hline \multicolumn{5}{|l|}{ PCDDs+PCDFs } \\
\hline US & $0.52-2.57$ & & 1995 & Shecter, et al.(1996) \\
\hline Germany & 1.3 & 93.5 & & Beck, et al.(1989) \\
\hline Germany & 2 (breast-fed infants 149 ) & & & Beck, et al.(1992) \\
\hline Germany & 1.2 & 85 & $1984-88$ & Fürst, et al.(1990) \\
\hline Germany & 0.88 & & $1993-1996$ & Rainer, et al.(1998) \\
\hline Germany & 1.60 (children $14-47$ mo. old) & & 1998 & Wittsiepe, et al.(2000) ${ }^{*}$ \\
\hline New Zealand & $0.18-0.44$ & $14.5-30.6$ & & Buckland, et al.(1998) \\
\hline Venetia & & 42 & 1994-1996 & Zanotto, et al.(1999) \\
\hline Japan & 0.89 & 44.69 & $1999-2000$ & Tsutsumi, et al.(2001) \\
\hline Japan & 0.47 & & 2002 & Ministry of Environment (2003) * \\
\hline Belgium & 1.00 & 65.3 & $2000-2001$ & Focant, et al.(2002) \\
\hline Spain & & 210 & 1996 & Domingo, et al.(1999) \\
\hline Spain & & 63.8 & 2002 & Bocio, et al.(2005) \\
\hline \multicolumn{5}{|c|}{$\mathrm{PCDDs}+\mathrm{PCDF}+\mathrm{PCBs}$} \\
\hline Netherlands & 1(median), 2(95 percentile) & & $1987-88$ & Theelen, et al.(1993) \\
\hline UK & (breast-fed infants 26-110) & 140 & 1992 & Wearne, et al (1996) \\
\hline UK & 2.4 (breast-fed infants 39-170) & & 1992 & Harrison, et al.(1998) \\
\hline US & $1.16-3.57$ & & 1995 & Shecter, et al (1996) \\
\hline US & 2.2-2.4(breast-fed infants 42 ) & & 1995 & Shecter, et al (2001) \\
\hline Norway & & $137-190$ & $1992-194$ & Becher, et al.(1998) \\
\hline New Zealand & $0.33-0.76$ & & & Buckland, et al.(1998) \\
\hline Japan & 2.25 & 112.61 & $1999-2000$ & Tsutsumi, et al.(2001) \\
\hline Japan & 1.3 & & 2002 & Ministry of Environment (2003)* \\
\hline Belgium & 2.04 & 132.9 & $2000-2001$ & Focant, et al.(2002) \\
\hline Netherlands & 1.2 (median), $1.9(90$ percentile) & & 1998-99 & Barrs, et al .(2004) \\
\hline
\end{tabular}

* Duplicate portion analysis. All other studies are based on the market basket method.

of the long-term intake, which is necessary for risk assessment of dioxins.

In contrast to adults, breast-fed babies have an extremely high dioxin intake. Based on the dioxin content in breast milk and the volume of milk consumed daily, the dioxin intake among breast-fed babies was estimated at 26-170 pg TEQ/kg/day $(11,20-22)$, which is much higher than the TDI. However, currently it is not recommended to refrain from breast-feeding, considering the relatively short duration of exposure and the overall merits of breast-feeding, such as immunologic protection, nutrition and mother-to-infant bonding. Several researchers reported that after the 1970's1980 's the content of PCDDs/PCDFs/PCBs in breast milk sharply declined in developed countries $(28,29)$.

\section{Blood levels of PCDDs/PCDFs/co-PCBs and related factors}

The body burden of dioxins can be assessed by measuring dioxin levels in blood lipid. However, the relationship of the blood levels with the total body burden and the concentrations in various organs may be influenced by factors such as the presence of severe weight loss (28) and hyperlipidemia, and percent body fat. Table 2 presents the mean or median dioxin concentrations in the blood among populations with no known accidental or occupational exposure (17, 30-39). Within the same population, the arithmetic mean is usually higher than the median, since the distribution of the blood levels of dioxins is positively skewed. As was the case for dietary intake, some reports did not analyze all 29 congeners/isomers of PCDDs/ PCDFs/co-PCBs with known TEFs, and not all studies used the same TEFs. The mean or median blood levels of PCDDs/PCDFs ranged from 9.8 to $40.8 \mathrm{pg}$ $\mathrm{TEQ} / \mathrm{g}$ lipid, and the mean or median blood contents of PCDDs/PCDFs/co-PCBs ranged from 16 to 43.8 pg TEQ/g lipid, with co-PCBs accounting for approximately $40 \%$ of the total TEQs.

Several researchers investigated the factors associated with the blood levels of dioxins. In general, blood concentrations of dioxins increase with age $(28,32,38,40)$. Serum levels of triglyceride were positively correlated with levels of dioxins in the blood not only in heavily exposed populations $(41,42)$ but also in the general population, even when expressed as pg TEQ/g lipid (38), which suggests that dioxins are more concentrated in triglyceride than other fractions of blood lipid. In Japan, serum levels of $\omega-3$ polyunsaturated fatty acids (eicosapentaenoic acid and docosahexaenoic acid), a biomarker of fish intake, and intake frequency of raw fish were reported to be positively 
Table 2. Blood levels of dioxin-related compounds (pg TEQ/g lipid) in general populations of various countries

\begin{tabular}{|c|c|c|c|c|c|}
\hline Country & No. of subjects & Mean or median & Range & Year of survey & References \\
\hline \multicolumn{6}{|c|}{ PCDDs+PCDFs } \\
\hline Canada & pooled sample & 14.6(mean) & & 1992 & Ayotte et al.(1997) \\
\hline Canada & 30 & 20.6(mean) & & 1994 & Ryan et al .(1997) \\
\hline Germany & 139 & 16.1(mean) & & 1996 & Päpke et al.(1998) \\
\hline Germany & 507 & 19.2-40.8(median) & 6.1-113.6 & $1991-6$ & Wittsiepe et al.(2000) \\
\hline Finland & 45 & 32 (median) & $12.0-81.0$ & 1998 & Kiviranta et al.(2000) \\
\hline Spain & 28 & 27.6 (mean) & $13.4-84.0$ & 1999 & Domingo et al.(2001) \\
\hline Japan & 50 & 16.4 (mean) & & $1993-4$ & Iida et al .(1999) \\
\hline Japan & 50 & $17.2-22.9$ (median) & $10.9-48.7$ & 1998 & Kumagai et al. $(2000,2002)$ \\
\hline Japan & 253 & 9.8(median) & 0.91-33 & 1999 & Arisawa et al.(2003) \\
\hline Japan & 8 & 20.2 (mean) & & 2000 & Tsuchiya et al.(2003) \\
\hline Japan & 259 & 14(median) & $0.61-56$ & 2002 & Ministry of Environment(2003) \\
\hline \multicolumn{6}{|c|}{$\mathrm{PCDDs}+\mathrm{PCDFs}+\mathrm{PCBs}$} \\
\hline Canada & pooled sample & 26.1(mean) & & 1992 & Ayotte et al.(1997) \\
\hline Canada & 30 & 36.3(mean) & & 1994 & Ryan et al.(1997) \\
\hline Japan & 39 & 21 (mean) & $9.1-37$ & $1993-4$ & Iida et al .(1999) \\
\hline Japan & 253 & 16-17(median) & $1.3-53$ & 1999 & Arisawa et al.(2003) \\
\hline Japan & 8 & 43.8(mean) & & 2000 & Tsuchiya et al.(2003) \\
\hline Japan & 259 & 23(median) & $1.6-110$ & 2002 & Ministry of Environment(2003) \\
\hline
\end{tabular}

associated with the total TEQs (38). In a Taiwanese population living in the vicinity of waste incinerators (mean PCDDs/PCDFs in blood=14-16 pg TEQ/g lipid), intake frequency of sea fish, sea food and canned fish over the previous 10 years was positively associated with higher blood levels of PCDDs/PCDFs (40). A survey conducted by the Japanese Ministry of the Environment (17) showed that median blood level of PCDDs/PCDFs/co-PCBs among persons living in dioxin-polluted areas in Osaka and Saitama Prefectures was $27 \mathrm{pg}$ TEQ/g lipid, which was not significantly different from that of the control population (23 $\mathrm{pg}$ TEQ/g lipid), suggesting that the contribution of air/soil pollution to the total body burden of dioxins was small. Among women, a larger number of breastfed children and longer duration of breast-feeding were associated with lower levels of PCDDs/PCDFs/ co-PCBs in the blood (28). Regarding the host factors, single nucleotide polymorphism of the CYPIAl gene was not associated with total TEQs in blood (39). It has been reported that dioxin levels in blood have been gradually decreasing with time in developed countries (28,32).

The reference range or upper normal limit for the blood levels of dioxins has not been determined. One reason for this may be that the association between exposure to low levels of PCDDs/PCDFs/co-PCB and health effects has not been definitely established. Another approach may be to estimate these values on the basis of the statistical distribution. In Japan, the $95^{\text {th }}$ percentile of the blood levels of dioxins was around $65 \mathrm{pg}$ TEQ/g lipid (17).
Potential health effects associated with low levels of exposure to PCDDs/PCDFs/PCBs

\section{Diabetes mellitus}

The association between dioxins and diabetes was firstly reported for occupationally exposed populations and subsequently investigated in the general population. In a longitudinal study with more than 20 years of followup, Henriksen et al. (43) found that the risk of diabetes significantly increased, and time to diabetes onset significantly decreased, among U.S. Air Force veterans who had been heavily exposed to Agent Orange and its contaminant, 2,3,7,8-TCDD, during the Vietnam War (serum 2,3,7,8-TCDD=10-618pg/g lipid). In a crosssectional study on chemical workers heavily exposed to 2,4,5-trichlorophenol (2,4,5-T) (National Institute for Occupational Safety and Health [NIOSH] cohort), the prevalence of diabetes among the exposed group $(\mathrm{N}=280$, mean serum $2,3,7,8-\mathrm{TCDD}=220 \mathrm{pg} / \mathrm{g}$ lipid) was not significantly different from that of the control group $(\mathrm{N}=260$, mean $=7 \mathrm{pg} / \mathrm{g}$ lipid). However, six of 10 workers with the highest serum 2,3,7,8 -TCDD levels ( $>1500 \mathrm{pg} / \mathrm{g}$ lipid) had diabetes (44). In a study by Steenland et al.(45), in which the data from the U.S. Air Force veterans (43) and the NIOSH cohort (44) were re-analyzed, a dose-response relationship between serum dioxin and prevalence of diabetes was observed only for Air Force veterans.

Longnecker et al.(46) reported that there was a significant dose-response relationship between the serum level of 2,3,7,8-TCDD and the prevalence of diabetes among 1,197 Air Force veterans with no history of occupational dioxin exposure. The prevalence odds ratio of diabetes in the highest quartile 
( $>5.2 \mathrm{pg} / \mathrm{g}$ lipid) was 1.71 (95\% CI 1.00-2.91) as compared with the lowest quartile $(<2.8 \mathrm{pg} / \mathrm{g}$ lipid). However, after adjustment for serum triglycerides, a potential confounder, the odds ratio was attenuated to 1.56 (95\% CI 0.91-2.67). The same research group also reported higher serum levels of PCBs among pregnant women with diabetes than among controls (47). However, because these two studies were crosssectional, it remains unclear whether exposure to 2 , 3,7,8-TCDD/PCBs increased the prevalence of diabetes, or diabetes altered the metabolism of 2,3,7,8TCDD/PCBs in the body. Considering all these findings taken together, it seems premature to conclude that exposure to background levels of dioxins increases the risk of diabetes. In the future, cohort studies of populations with background levels of exposure will be required.

\section{Endometriosis}

The association between exposure to dioxin-related compounds and endometriosis was firstly found in animal experiments, and subsequently investigated in highly exposed human populations, followed by general populations. Endometriosis is important in that this is one of the most sensitive adverse effects observed in animal experiments, and has been used as a basis for the calculation of TDI (4). In 1993, Rier et al. (5) reported that the incidence and the severity of endometriosis increased in a dose-dependent manner in rhesus monkeys fed a diet containing 5-25 ppt of 2,3,7,8-TCDD for 4 years. An additional study conducted 13 years after the termination of exposure showed that serum levels of not only 2,3,7,8-TCDD but also dioxin-like PCBs (International Union for Pure and Applied Chemistry [IUPAC] No.77 and 126) were increased in TCDD-treated monkeys, especially among those with endometriosis, suggesting the involvement of dioxin-like PCBs in the development of the disease (48).

In Seveso, Italy, where heavy exposure to 2,3,7,8TCDD occurred because of an explosion at a chemical plant, a historical cohort study was carried out (49). Among 601 women, 19 cases of endometriosis were identified during 20 years of follow-up. The multivariate relative risks for women with 2,3,7,8-TCDD levels of $>100$ ppt and $20.1-100$ ppt were 2.1 (95\% CI 0.5-8.0) and 1.2 (95\% CI 0.3-4.5), respectively, as compared with women with $<=20 \mathrm{ppt}$. It was pointed out that nondifferential misclassification of disease status, because of inability to perform laparoscopy for every woman, may have led to the underestimation of relative risks (49).
Several case-control studies have been performed on populations without accidental or occupational exposure. An Israeli study (50) reported that 2,3,7,8TCDD was detected in $8 / 44(18 \%)$ of women with endometriosis, as compared with $1 / 35$ (3\%) of control women. The odds ratio associated with high blood 2,3,7,8-TCDD levels was estimated at 7.6 (95\% CI 0.87169.7). However, the limitation of this study was that statistical power was lacking, and only 2,3,7,8-TCDD but no other congeners/isomers were analyzed. In a Belgian study involving 42 cases and 27 controls with mechanical infertility (51), there were no significant differences in the blood levels of total TEQs, as determined by the chemical-activated luciferase gene expression (CALUX)-bioassay, or of one co-PCB (No. 118 ) or three non-coplanar PCBs (No.138,153 and 180). On the other hand, when a cut-off point of 100 pg-TEQ/g lipid was used, the odds ratio of endometriosis was elevated but not significantly $(4.56,95 \% \mathrm{CI}$ 0.48-43.6). In a recent small case-control study (23 cases and 17 controls) performed in Belgium and Italy, there was no significant difference in the total TEQs in blood between cases and controls (52). Thus, at present it is not clear whether exposure to background levels of dioxins increases the risk of endometriosis. In the future, larger epidemiologic studies with sufficient statistical power will be required. For instance, if the true odds ratio is 2-3, an unmatched case-control study would require 99-282 women for both cases and controls, assuming that the prevalence of endometriosis among the source population is $10 \%$ and $\alpha$ and $\beta$ are set to 0.05 (two-tailed) and 0.20 , respectively (53).

\section{Thyroid function}

In animal experiments, exposure to PCDDs/PCDFs, and PCBs or their hydroxylated metabolites influences the hypothalamo-pituitary-thyroid axis by various mechanisms (54), although the direction of the effects may vary according to the animal species (55). In rats exposed to $2,3,7,8-\mathrm{TCDD}$ or PCBs, serum thyroxine (T4) decreased and secretion of thyroid stimulating hormone (TSH) from the pituitary increased. Exposure to 2,3, 7,8,-TCDD or co-PCBs induced the enzyme T4-uridine diphosphoglucuronyl-transferase-1 (UDPGT-1) in the liver by an Ah-receptor-mediated mechanism and thereby increased hepatic glucuronidation and biliary excretion of T4 (56-58). It has also been shown that hydroxylated PCBs and PCDDs/PCDFs have higher affinity than $\mathrm{T} 4$ for the transthyretin (thyroxine-binding prealbumin), the major T4 transport protein in the plasma of rodents, which may lead to the inhibition of the T4 transportation to the brain (59). In fetal rats, 
Table 3. Effects of dioxin exposure on thyroid function in adults and infants

\begin{tabular}{|c|c|c|c|c|c|c|}
\hline Population & No. of subjects & Mean exposure level (pg/g lipid) & $\mathrm{T} 4$ & free $\mathrm{T} 4$ & TSH & References \\
\hline \multicolumn{7}{|l|}{ Adults } \\
\hline BASF cohort (Germany) & 138 & $<1-553^{*}$ (blood, 2,3,7,8-TCDD) & $\uparrow$ & & $\Leftrightarrow$ & Ott, et al.(1994) \\
\hline US(2,4,5-T exposed) & 281 & 220 (blood, 2,3,7,8-TCDD) & $\uparrow$ & $\uparrow$ & $\Leftrightarrow$ & Calvert, et al.(1999) \\
\hline Yusho patients & 16 & 222.4(blood, TEQ) & $\Leftrightarrow$ & $\Leftrightarrow$ & $\Leftrightarrow$ & Nagayama, et al.(2001) \\
\hline US Air Force veterans & 275 & 45.7(blood, 2,3,7,8-TCDD) & $\Leftrightarrow$ & $\Leftrightarrow$ & $\uparrow$ & Pavuk, et al.(2003) \\
\hline Netherlands (pregnant women) & 78 & 74.9(milk, TEQ) & $\downarrow$ & & $\Leftrightarrow$ & Koopman-Esseboom, etal. (1994) \\
\hline Australia(2,4,5-T exposed) & 37 & 2.6-8.1(blood,2,3,7,8-TCDD) & $\Leftrightarrow$ & & $\downarrow$ & Johnson, et al.(2001) \\
\hline \multicolumn{7}{|l|}{ Infants } \\
\hline Netherlands(0-11 weeks) & 15 & 37.5(milk, TEQ) & $\uparrow$ & $\uparrow * *$ & $\uparrow$ & Plium, et al.(1993) \\
\hline Netherlands( 2 weeks $)$ & 39 & 72.4(milk, TEQ) & $\downarrow$ & $\Leftrightarrow$ & $\uparrow$ & Koopman-Esseboom, et al.(1994) \\
\hline Japan(1 year) & 37 & 25.7(milk, TEQ) & $\downarrow$ & $\Leftrightarrow$ & $\Leftrightarrow$ & Nagayama, et al.(1996) \\
\hline Japan(1 year) & 337 & 13.1-29.5(milk, TEQ) & $\Leftrightarrow$ & $\Leftrightarrow$ & $\Leftrightarrow$ & Matsumura, et al.(2001) \\
\hline
\end{tabular}

* range, ${ }^{* *}$ T4/TBG ratio.

T4 levels in the forebrain and cerebellum decreased following maternal exposure to PCBs, though T3 levels remained unchanged because of compensatory induction of type II 5'-deinodinase (60).

In humans, data about the association between exposure to dioxin-related compounds and thyroid function have been inconsistent for both adults and infants, though the blood levels of T4, free T4 and TSH are generally within the normal range even in heavily exposed subjects. Ott et al . (61) reported that serum T4 and thyroxine-binding globulin (TBG) levels significantly increased with increasing current TCDD concentrations in the blood among 138 members of the BASF cohort who had been heavily exposed to 2,4,5-T and 2,3,7,8-TCDD. Among 281 U.S. workers exposed to 2,4,5-T, there was also a significant increase in the free T4 index but no change in the serum TSH level (44). On the other hand, in 16 patients with Yusho, there was no association between total TEQ and serum concentrations of triiodothyronine (T3), T4, free T4 or TSH 27 years after the outbreak, despite extremely high TEQs in the blood (median=222.4 pg/g fat) (62). Pavuk et al . (63) reported that there was no difference in the serum T4 levels or T3\% uptake between US Air Force veterans who had been heavily exposed to TCDD (median blood TEQ $=45.7 \mathrm{pg} / \mathrm{g}$ fat) and control Air Force veterans. However, the serum levels of TSH were significantly higher in the exposed group.

In a Dutch study of pregnant women with no known accidental or occupational exposure (mean PCDDs/ PCDFs/co-PCB TEQ in the breast milk=74.9 pg TEQ/g lipid), serum levels of T4 and T3 significantly decreased as the dioxin levels in the breast milk increased (64). In contrast, among Australian men exposed to very low levels of 2,4,5-T (mean serum 2,3,7,8-TCDD=2.6$8.1 \mathrm{ppt}$ ), serum levels of TSH (Spearman $\mathrm{r}=-0.4$ ) but not $\mathrm{T} 4$ were significantly and negatively correlated with TCDD (65).

In infants, two studies, one conducted in the Netherlands (at 2 weeks of age) (64) and the other in Japan (at 1 year of age) (66), found that decreased serum T4 levels were related to high TEQ levels in breast milk. In contrast, there were increased blood levels of total T4, T4/TBG ratio and TSH among infants (aged 11 weeks) with high PCDDs/PCDFs TEQs in another Dutch study (67). In another Japanese study, there were no differences in the blood levels of T4, T3, free T4 or TSH between breast-fed and bottle-fed infants aged 1 year (68). The reason for the discrepancy among these studies remains unknown; however, the decreased T4 and the increased TSH levels in the blood of infants reported by Koopmann-Esseboom et al.(64) were consistent with those of experimental studies on rats $(56,57)$. Since thyroid hormones are essential for normal brain development during fetal and neonatal periods, some researchers proposed the decreased serum $\mathrm{T} 4$ levels observed among pregnant women $(64)$ and infants $(64,66)$ as one of the possible mechanisms linking exposure to PCBs/dioxins and impaired neurodevelopment of children, as discussed below.

\section{Neurodevelopment of infants}

The association between exposure to PCDDs/ $\mathrm{PCDF} / \mathrm{PCBs}$ and neurodevelopment of infants has been reported mainly in relation to non-dioxin-like PCBs (69). An impairment of neuropsychological development was reported among Taiwanese children born to mothers who had been accidentally exposed to high levels of PCBs and other thermally degraded substances, including PCDFs, through contaminated rice oil (70). Animal experiments also showed that PCBs have direct toxic effects on neurotransmission and neural network formation that are not mediated 
Table 4. Effects on growth and neurodevelopment associated with exposure to PCBs and/or PCDDs/PCDFs/co-PCBs

\begin{tabular}{|c|c|c|c|c|c|}
\hline Cohort & $\begin{array}{l}\text { No. of } \\
\text { subjects }\end{array}$ & Age & Exposure variables & Effects & References \\
\hline \multirow[t]{4}{*}{ North Carolina } & 912 & $0 \mathrm{~m}$ & $\begin{array}{l}\text { Prenatal total PCBs exposure } \\
\text { (Breast milk }(0 \mathrm{w}) \text { total PCBs) }\end{array}$ & $\begin{array}{l}\text { Birth weight } \Leftrightarrow \\
\text { Head circumference } \Leftrightarrow \\
\text { NBAS tonicity } \downarrow \\
\text { NBAS reflexes } \downarrow\end{array}$ & Rogan, et al.(1986) \\
\hline & 802 & $\begin{array}{l}6 \mathrm{~m} \\
12 \mathrm{~m}\end{array}$ & Prenatal total PCBs exposure & $\begin{array}{l}\text { Bayley Scales psychomotor } \downarrow \\
\text { Bayley Scales psychomotor } \downarrow\end{array}$ & Gladen, et al.(1988) \\
\hline & 676 & $18 \mathrm{~m}$ & Prenatal total PCBs exposure & $\begin{array}{l}\text { Bayley Scales mental } \Leftrightarrow \\
\text { Bayley Scales psychomotor } \Leftrightarrow\end{array}$ & Rogan, et al.(1991) \\
\hline & 670 & $24 \mathrm{~m}$ & Prenatal total PCBs exposure & $\begin{array}{l}\text { Bayley Scales mental } \Leftrightarrow \\
\text { Bayley Scales psychomotor } \downarrow\end{array}$ & \\
\hline \multirow[t]{10}{*}{ Netherlands } & 207 & $\begin{array}{l}0 \mathrm{~m} \\
0-3 \mathrm{~m} \\
3-42 \mathrm{~m}\end{array}$ & $\begin{array}{l}\text { Cord PCBs, maternal PCBs } \\
\text { Cord PCBs, maternal PCBs } \\
\text { Cord PCBs, maternal PCBs }\end{array}$ & $\begin{array}{l}\text { birth weight } \downarrow \\
\text { growth rate } \downarrow \\
\text { growth rate } \Leftrightarrow\end{array}$ & Patandin, et al.(1998) \\
\hline & 209 & $0 \mathrm{~m}$ & $\begin{array}{l}\text { Breast milk PCBs }(2 \mathrm{w}) \\
\text { Breast milk total TEQ }(2 \mathrm{w})\end{array}$ & $\begin{array}{l}\text { Prechtl neurological } \\
\text { optimality score } \downarrow \text { (hypotonic) }\end{array}$ & Huisman, et al.(1995a) \\
\hline & 207 & $3 \mathrm{~m}$ & Maternal plasma PCBs & Bayley Scales psychomotor $\downarrow$ & Koopman \\
\hline & & $7 \mathrm{~m}$ & $\begin{array}{l}\text { Breast milk total PCBs-dioxins TEQ } \\
\text { (postnatal exposure) }\end{array}$ & Bayley Scales psychomotor $\downarrow$ & -Esseboom, et al.(1996) \\
\hline & & $18 \mathrm{~m}$ & $\begin{array}{l}\text { Perinatal PCBs, total TEQs } \\
\text { Postnatal PCBs, total TEQs }\end{array}$ & $\begin{array}{l}\text { Bayley Scales mental, psychomotor } \Leftrightarrow \\
\text { Bayley Scales mental, psychomotor } \Leftrightarrow\end{array}$ & \\
\hline & 418 & $18 \mathrm{~m}$ & Cord PCBs, maternal PCBs & Prechtl Neurological & \\
\hline & 395 & $42 \mathrm{~m}$ & Maternal plasma PCBs & $\begin{array}{l}\text { Optimality score } \downarrow \\
\text { Kaufman Assessment }\end{array}$ & Huisman, et al.(1995b) \\
\hline & & & & $\begin{array}{l}\text { Battery for Children } \\
\text { Overall cognitive } \downarrow \\
\text { Sequential } \downarrow \\
\text { Simultaneous } \downarrow\end{array}$ & Patandin, et al.(1999) \\
\hline & 394 & $42 \mathrm{~m}$ & Maternal plasma PCBs & Towen/Hampel & \\
\hline & & & $\begin{array}{l}\text { Cord plasma PCBs } \\
42 \text { mo. plasma PCBs }\end{array}$ & Neurological condition $\Leftrightarrow$ & Lanting, et al.(1999) \\
\hline \multirow[t]{5}{*}{ Germany } & 171 & $7 \mathrm{~m}$ & Breast milk(2,4 w) PCB 138,153,180 & $\begin{array}{l}\text { Bayley Scales mental } \downarrow \text { motor } \Leftrightarrow \\
\text { Fagan visual recognition memory } \Leftrightarrow\end{array}$ & Winneke, et al.(1998) \\
\hline & 171 & $30 \mathrm{~m}$ & $\begin{array}{l}\text { Breast milk(2 w) PCB 138,153,180 } \\
\text { (prenatal exposure) }\end{array}$ & $\begin{array}{l}\text { Bayley Scales mental } \downarrow \\
\text { Bayley Scales motor } \downarrow\end{array}$ & Walcowiak, et al.(2000) \\
\hline & & $42 \mathrm{~m}$ & Breast milk(2w) PCB 138,153,180 & Kaufman mental development $\downarrow$ & \\
\hline & & & Milk PCBs $\mathrm{x}$ duration of breast-feeding & Kaufman mental development $\downarrow$ & \\
\hline & & & 42 mo. plasma PCBs & Kaufman mental development $\downarrow$ & \\
\hline
\end{tabular}

by Ah-R (71). Cohort studies have also been conducted on children born to mothers who had consumed PCBscontaminated fishes from Lake Michigan (72) and Lake Ontario (73), and contaminated whale meat and blubber from the Faroe Islands (74). However, these studies on accidental (70) or environmental exposure (72-74) were excluded from this review because the exposure levels of PCBs in such studies may be higher than the levels in the general population.

Several longitudinal studies in the U.S.(75-78), the Netherlands (79-84) and Germany $(85,86)$ investigated the effects of background exposure to PCBs or dioxins on mental and psychomotor development of infants (Table 4). In North Carolina, U.S., approximately 900 pairs of mothers and infants were initially enrolled, and total PCBs in breast milk (0 week) was measured as an index of prenatal exposure. The median total PCB concentration in the breast milk at birth was reported to be $1,770 \mathrm{ng} / \mathrm{g}$ lipid (75). However, this value may be overestimated because of the old analytical method used (69). No PCDDs/PCDFs congeners/isomers in breast milk were analyzed. There was no association between prenatal PCBs exposure and weight or head circumference at birth. However, high exposure was associated with hypotonicity and hyporeflexia, as assessed by the Neonatal Behavioral Assessment Scale (NBAS) (76). The Bayley Psychomotor Scales were decreased at 6,12 and 24 months in relation to high transplacental exposure, but not postnatal exposure through breast milk $(77,78)$. No effects on mental development were observed.

In the Netherlands cohort, approximately 400 mother- 
infant pairs, 200 each in Groningen and Rotterdam, were enrolled (79). Umbilical cord plasma and maternal plasma PCBs (No.118,138,153 and 180) were measured as an index of prenatal exposure, and PCDDs/ PCDFs/PCBs content in breast milk (at 2 weeks) multiplied by the number of weeks of breast-feeding was used as an index of lactational exposure to these substances. The median total PCBs concentration in cord plasma, maternal plasma and breast milk was $0.40 \mu \mathrm{g} / 1,2.04 \mu \mathrm{g} / 1$ and $391.5 \mathrm{ng} / \mathrm{g}$ lipid, respectively, and the median total PCDDs/PCDFs/co-PCBs in breast milk was $64.8 \mathrm{pg}$ TEQ/g lipid. Prenatal PCBs exposure was inversely associated with birth weight and growth rate during 0-3 months (change in weight, length and head circumference) (79). There were also negative effects on motor and cognitive development, as assessed by Bayley Psychomotor Scales at 3 and 7 months (80) and Kaufman Assessment Battery for Children at 42 months (81), respectively, mainly in relation to prenatal $\mathrm{PCBs}$ and partly in relation to postnatal PCDDs/PCDFs/co-PCBs exposure. On the other hand, breast-feeding itself had a positive effect on the Bayley Psychomotor Scales at 7 months. The Prechtl Neurological Optimality Score at 0 month decreased as the combined pre-and early neonatal exposure (both dioxin-like and non-dioxin-like PCBs, and PCDDs/ PCDFs/co-PCBs-TEQ in breast milk at 2 weeks) increased (82). The same score at 18 months decreased as the prenatal PCBs exposure (cord and maternal PCBs) increased (83). At 42 months, there was no significant association between PCBs or PCDDs/PCDFs/ co-PCBs exposure and neurological condition as assessed by the Towen/Hempel method (84). There was no significant relationship between the serum thyroid hormone levels and the mental or psychomotor development at any age (80).

In Düsseldorf, Germany, 171 healthy mother-infant pairs were initially recruited (85). The sum of the levels of three non-dioxin-like PCBs (No.138, 153 and 180) in breast milk (at 2 weeks) were used as an index of prenatal exposure, and milk PCBs multiplied by duration of breast-feeding and plasma levels of PCBs in infants were used as an index of postnatal exposure. The median total PCBs concentration in cord plasma and breast milk was $0.39 \mu \mathrm{g} / \mathrm{l}$ and $404 \mathrm{ng} / \mathrm{g}$ lipid, respectively. No PCDDs/PCDFs concentrations in cord plasma or breast milk were analyzed. A negative association was observed between prenatal exposure and neurodevelopment, as assessed by the Bayley Mental/Motor Scales of Infant Development at 30 months and the Kaufman Assessment Battery for Children (simultaneous and sequential information processing) at 42 months, after adjustment for various potential confounders, including smoking, alcohol drinking and parental education (86). There was also an inverse association between postnatal PCBs exposure and Kaufman Assessment Battery for Children at 42 months. On the other hand, a good home environment compensated for the adverse effects of PCBs exposure.

In summary, inhibitory effects on motor and mental development of infants have been observed in relation to background exposure to PCBs/dioxins, especially trans-placental PCBs, although there are some inconsistencies in the exposure media and outcome variables. The lack of significant association between serum thyroid hormone levels and mental/motor development (80) suggests the involvement of nonthyroid-mediated mechanisms. At all events, efforts should be made to further decrease exposure levels among women of reproductive age as much as possible, by reducing the release of PCDDs/ PCDFs/ $\mathrm{PCBs}$ into the environment. In the future, longitudinal studies of the neurodevelopment of infants should be performed on fish-eating populations such as the Japanese, because fish is a major source of exposure to dioxin-like and non-dioxin-like PCBs.

\section{ACKNOWLEDGEMENTS}

The authors are deeply indebted to Prof. Shohei Ohgi, Department of Rehabilitation, Seirei Christopher College, Hamamatsu, Japan, for his useful comments on the neurodevelopment of children.

\section{REFERENCES}

1. WHO, IARC : IARC Monographs on the Evaluation of Carcinogenic Risks to Humans. Vol69 Polychlorinated Dibenzo-para-dioxins and Polychlorinated Dibenzofurans. IARC, Lyon, France, 1997

2. Safe $\mathrm{S}$ : Polychlorinated biphenyls (PCBs), dibenzo$p$-dioxins (PCDDs), dibenzofurans (PCDFs), and related compounds : Environmental and mechanistic considerations which support the development of toxic equivalency factors (TEFs). Crit Rev Toxicol $21: 51-88,1990$

3. Van den Berg M, Birnbaum L, Bosveld ATC, Brunstrom B, Cook P, Feeley M, Giesy JP, Hanberg A, Hasegawa R, Kennedy SW, Kubiak T, Larsen JC, van Leeuwen FXR, Liem AKD, Nolt C, Peterson RE, Poellinger L, Safe S, Schrenk D, Tillitt D, 
Tysklind M, Younes M, Warn F, Zacharewski T: Toxic Equivalency Factors (TEFs) for PCBs, PCDDs, PCDFs for Humans and Wildlife. Environ Health Perspect 106 : 775-792, 1998

4. van Leeuwen FXR, Feeley M, Schrenk D, Larsen JC, Farland W, Younes M : Dioxins : WHO's tolerable daily intake (TDI) revisited. Chemosphere 40 : 1095-1101, 2000

5. Rier SE, Martin DC, Bowman RE, Dmowski P, Becker JL: Endometriosis in Rhesus Monkeys (Macca mulatta) following chronic exposure to 2,3,7,8-tetrachlorodibenzo- $p$-dioxin. Fundam Appl Toxicol 21 : 433-441, 1993

6. Gray LE, Ostby JS, Kelce WR : A dose-response analysis of the reproductive effects of a single gestational dose of 2,3,7,8-tetrachlorodibenzop-dioxin in male Long Evans Hooded rat offspring. Toxicol Appl Pharmacol 146:11-20, 1997

7. Steenland K, Piacitelli L, Deddens J, Fingerhut M, Chang LI : Cancer, heart disease, and diabetes in workers exposed to 2,3,7,8-tetrachlorodibenzop-dioxin. J Natl Cancer Inst 91 : 779-786, 1999

8. Schecter A, Cramer P, Boggess K, Stanley J, Olson JR, Kessler H : Dioxin intake from U.S. food: Results from a new nationwide food survey. Organohalogen Compounds $28: 320-324,1996$

9. Theelen RMC, Liem AKD, Solb W, van Wijnen $\mathrm{JH}$ : Intake of 2,3,7,8 chlorine substituted dioxins, furans, and planar PCBs from food in The Netherlands : median and distribution. Chemosphere 27 : 1625-1635, 1993

10. Beck H, Eckart K, Mathar W, Wittkowski R : PCDD and PCDF body burden from food intake in the federal republic of Germany. Chemosphere $18: 417-424,1989$

11. Beck H, Dro A, Mathar W : PCDDs, PCDFs, and related contaminants in the German food supply. Chemosphere 25 : 1539-1550, 1992

12. Fürst P, Fürst C, Groebel W : Levels of PCDDs and PCDFs in food-stuffs from the Federal Republic of Germany. Chemosphere 20 : 787-792, 1990

13. Rainer M : Update of PCDD/PCDF-Intake from food in Germany. Chemosphere 37:1687-1698, 1998

14. Buckland SJ, Scobie SE, Hannah ML, Heslop V: Concentrations of PCDDs, PCDFs, and PCBs in New Zealand retail foods and an assessment of dietary exposure. Organohalogen Compounds $38: 71-74,1998$

15. Zanotto E, Alcock RE, Della Sala S, D'Andrea F, Green N, Jones KC, Marcomini A, Sweetman AJ, Wood J:PCDD/Fs in Venetian foods and a quantitative assessment of dietary intake. Organohalogen Compounds 44 : 13-16, 1999

16. Tsutsumi T, Yanagi T, Nakamura M, Kono Y, Uchibe H, lida T, Hori T, Nakagawa R, Tobiishi K, Matsuda R, Sasaki K, Toyoda M : Update of daily intake of PCDDs, PCDFs, and dioxin-like PCBs from food in Japan. Chemosphere 45:11291137, 2001

17. Ministry of the Environment, Japan. Results of the survey on the body burden of dioxins in humans, Tokyo, 2002

18. Focant JF, Eppe G, Pirard C, Massart AC, Andre $\mathrm{JE}$, de Pauw $\mathrm{E}$ : Levels of congener distributions of PCDDs, PCDFs and non-ortho PCBs in Belgian foodstuffs. Assessment of dietary intake. Chemosphere 48 : 167-179, 2002

19. Domingo JL, Schuhmacher M, Granero S, Llobet $\mathrm{J} \mathrm{M}:$ PCDDs and PCDFs in food samples from Catalonia, Spain. An assessment of dietary intake. Chemosphere 38 : 3517-3528, 1999

20. Wearne SJ, Harrison N, de M Gem MG, Startin JR, Wright C, Kelly M, Robinson C, White S, Hardy $\mathrm{D}$, Edinburgh V : Time trends in human dietary exposure to PCDDs, PCDFs and PCBs in the UK. Organohalogen Compounds 30 : 1-6, 1996

21. Harrison N, Wearne S, de M Gem MG, Gleadle A, Startin J, Thorpe S, Wright C, Kelly M, Robinson C, White S, Hardy D, Edinburgh V : Time trends in human dietary exposure to PCDDs, PCDFs and PCBs in the UK. Chemosphere 37: 1657-1670, 1998

22. Schecter A, Cramer P, Boggess K, Stanley J, Päpke O, Olson J, Silver A, Schmitz M : Intake of dioxins and related compounds from food in the U.S. population. J Toxicol Environ Health $63: 1-18,2001$

23. Becher G, Eriksen GS, Lund-Larsen K, Skaare JU, Schlabach M, Alexander J : Dietary exposure and human body burden of dioxins and dioxinlike PCBs in Norway. Organohalogen Compounds 38 : 79-82, 1998

24. Baars AJ, Bakker MI, Baumann RA, Boon PE, Freijer JI, Hoogenboom LAP, Hoogerbrugge R, van Klaveren JD, Liem AKD, Traag WA, de Vries $\mathrm{J}$ : Dioxins, dioxin-like PCBs and non-dioxin-like PCBs in foodstuffs: occurrence and dietary intake in The Netherlands. Toxicol Lett $151: 51-61,2004$

25. Wittsiepe J, Schrey P, Wilhelm M : Dietary intake of PCDD/F by small children with different food consumption measured by the duplicate method. Chemosphere $43: 881-887,2001$

26. Bocio A, Domingo JL:Daily intake of polychlo- 
rinated dibenzo-p-dioxins/polychlorinated dibenzofurans (PCDD/PCDFs) in foodstuffs consumed in Tarragona, Spain : a review of recent studies (2001-2003) on human PCDD/PCDF exposure through the diet. Environ Res $97: 1-9,2005$

27. Willett $W$ : Nutritional Epidemiology Second Edition. Oxford University Press, New York Oxford, 1998

28. Päpke O. PCDD/PCDF : Human background data for Germany, a 10-year experience. Environ Health Perspect 106 (Suppl 2) : 723-731, 1998

29. Konishi Y, Kuwabara K, Hori S : Continuous surveillance of organochlorine compounds in human breast milk from 1972 to 1998 in Osaka, Japan. Arch Environ Contam Toxicol 40 : 571-578, 2001

30. Ayotte P, Dewailly E, Ryan JJ, Bruneau S, Lebel $\mathrm{G}$ : PCBs and dioxin-like compounds in plasma of adult Inuit living in Nunavik (Arctic Quebec). Chemosphere 34 : 1459-1468, 1997

31. Ryan JJ, Dewailly E, Gilman A, Laliberte C, Ayotte $\mathrm{P}$, Rodrigue J : Dioxin-like compounds in fishing people from the lower north shore of the St. Lawrence River, Quebec, Canada. Arch Environ Health $52: 309-316,1997$

32. Wittsiepe J, Schrey P, Ewers U, Wilhelm M, Selenka $\mathrm{F}$ :Decrease of PCDD/F levels in human bloodTrend analysis for the German population, 19911996. Environ Res A83 : 46-53, 2000

33. Kiviranta H, Vartiainen T, Verta M, Tuomisto JT, Tuomist $\mathrm{J}$ : High fish-specific dioxin concentrations in Finland. Lancet $355:$ 1883-1885, 2000

34. Iida T, Hirakawa $H$, Matsueda $T$, Takenaka S, Nakagawa R: Polychlorinated dibenzo- $p$-dioxin and related compounds: the blood levels of young Japanese women. Chemosphere 38:3497-3502, 1999

35. Kumagai S, Koda S, Miyakita T, Yamaguchi H, Katagi K, Yasuda N: Polychlorinated dibenzo$p$-dioxin and dibenzofuran concentrations in the serum samples of workers at continuously burning municipal waste incinerators in Japan. Occup Environ Med 57 : 204-210, 2000

36. Kumagai S, Koda S, Miyakita T, Ueno M : Polychlorinated dibenzo- $p$-dioxin and dibenzofuran concentrations in serum samples of workers at intermittently burning municipal waste incinerators in Japan. Occup Environ Med 59:362-368, 2002

37. Domingo JL, Schuhmacher M, Agramunt MC, Müller L, Neugebauer F : Levels of metals and organic substances in blood and urine of workers at a new hazardous waste incinerator. Int Arch
Occup Environ Health 74 : 263-269, 2001

38. Arisawa K, Matsumura T, Tohyama C, Saito H, Satoh H, Nagai M, Morita M, Suzuki T: Fish intake, plasma $\omega-3$ polyunsaturated fatty acids, and polychlorinated dibenzo-p-dioxins/polychlorinated dibenzo-furans and co-planar polychlorinated biphenyls in the blood of the Japanese population. Int Arch Occup Environ Health 76 : 205-215, 2003

39. Tsuchiya Y, Nakai S, Nakamura K, Hayashi K, Nakanishi J, Yamamoto M : Effects of dietary habits and CYP $1 \mathrm{~A} 1$ polymorphisms on blood dioxin concentrations in Japanese men. Chemosphere $52: 213-219,2003$

40. Chen HL, Lee CC, Liao PC, Guo YL, Chen CH, $\mathrm{Su} \mathrm{HJ}$ : Associations between dietary intake and serum polychlorinated dibenzo- $p$-dioxin and dibenzofuran $(\mathrm{PCDD} / \mathrm{F})$ levels in Taiwanese. Environ Res $91: 172-178,2003$

41. Hirota Y, Kataoka K, Tokunaga S, Hirohata T, Shinohara S, Tokiwa $\mathrm{H}$ : Association between blood polychlorinated biphenyl concentration and serum triglyceride level in chronic "Yusho" (polychlorinated biphenyl poisoning) patients. Int Arch Occup Environ Health 65 : 221-225, 1993

42. Calvert GM, Wille KK, Sweeney MH, Fingerhut MA, Halperin WE : Evaluation of serum lipid concentrations among U.S. workers exposed to 2,3,7,8-tetrachlodibenzo- $p$-dioxin. Arch Environ Health $51: 100-107,1996$

43. Henriksen GL, Ketchum NS, Michalek JE, Swaby JA : Serum dioxin and diabetes mellitus in veterans of Operation Ranch Hand. Epidemiology $8: 252-258,1997$

44. Calvert GM, Sweeney MH, Deddens J, Wall DK: Evaluation of diabetes mellitus, serum glucose, and thyroid function among United States workers exposed to 2,3,7,8-tetrachlorodibenzo-p-dioxin. Occup Environ Med 56 : 270-276, 1999

45. Steenland K, Calvert G, Ketchum N, Mickalek $\mathrm{J}$ : Dioxin and diabetes mellitus: An analysis of the combined NIOSH and Ranch Hand data. Occup Environ Med 58 : 641-648, 2001

46. Longnecker MP, Mickalek JE : Serum dioxin level in relation to diabetes mellitus among Air Force Veterans with background levels of exposure. Epidemiology 11 : 44-48, 2000

47. Longnecker MP, Klebanoff MA, Brock JW, Zhou $\mathrm{H}$ : Polychlorinated biphenyl serum levels in pregnant subjects with diabetes. Diabetes Care 24 : 1099-1101, 2001

48. Rier SE, Turner WE, Martin DC, Morris R, Lucier 
GW, Clark GC: Serum levels of TCDD and dioxinlike chemicals in Rhesus Monkeys chronically exposed to dioxin : correlation of increased serum PCB levels with endometriosis. Toxicol Sci 59: 147-159, 2001

49. Eskenazi B, Mocarelli P, Warner M, Samuels S, Vercellini P, Olive D, Needham LL, Patterson DG, Brambilla P, Gavoni N, Casalini S, Panazza S, Turner W, Gerthoux PM : Serum dioxin concentrations and endometriosis: a cohort study in Seveso, Italy. Environ Health Perspect 110 : 629-634, 2002

50. Mayani A, Barel S, Soback S, Almagor M : Dioxin concentrations in women with endometriosis. Hum Reproduct 12 : 373-375, 1997

51. Pauwels A, Schepens PJC, Hooghe TD, Delbeke L, Dhont M, Brouwer A, Weyler J : The risk of endometriosis and exposure to dioxins and polychlorinated biphenyls : a case-control study of infertile women. Hum Reproduct 16:2050-2055, 2001

52. Felip ED, Porpora MG, di Domenico A, Ingelide AM, Cardelli M, Cosmi EV, Donnez J : Dioxinlike compounds and endometriosis:a study on Italian and Belgian women of reproductive age. Toxicol Lett 150 : 203-209, 2004

53. Schlesselman:Case-control Studies. Design, Conduct, Analysis. Oxford University Press, New York Oxford, 1982

54. Porterfield SP:Thyroidal dysfunction and environmental chemicals-potential impact on brain development. Environ Health Perspect 108 (Suppl) : 433-438, 2000

55. Henry EC, Gasiewicz TA : Changes in thyroid hormones and thyroxine glucuronidation in hamsters compared with rats following treatment with 2,3,7,8-tetrachlorodibenzo-p-dioxin. Toxicol Appl Pharmacol 89 : 165-174, 1987

56. Bastomsky $\mathrm{CH}$. Enhanced thyroxine metabolism and high uptake goiters in rats after a single dose of 2,3,7,8-tetrachlorodibenzo-p-dioxin. Endocrinology $101: 292-296,1977$

57. Van Birgelen APJM, Smit EA, Kampen IM, Groeneveld CN, Fase KM, Van der Kolk J, Poiger H, Van den Berg M, Koeman JH, Brouwer A : Subchronic effects of 2,3,7,8-TCDD or PCBs on thyroid hormone metabolism: use in risk assessment. Eur J Pharmacol 293 : 77-85, 1995

58. Schuur AG, Boekhorst FM, Brouwer A, Visser TJ : Extrathyroidal effects of 2,3,7,8-tetrachlorodibenzo$p$-dioxin on thyroid hormone turnover in male Sprague-Dawley rats. Endocrinology 138:3727-
3734, 1997

59. Lans MC, Spiertz C, Brower A, Koeman JH : Different competition of thyroxine binding to transthyretin and thyroxine-binding globulin by hydroxy-PCBs, PCDDs and PCDFs. Eur J Pharmacol 270 : 129-136, 1994

60. Morse DC, Wehler EK, Wesseling W, Koeman $\mathrm{JH}$, Brouwer A : Alterations in rat brain thyroid hormone status following pre-and postnatal exposure to polychlorinated biphenyls (Aroclor 1254). Toxicol Appl Pharmacol 136 : 269-279, 1996

61. Ott MG, Zober A, Germann C : Laboratory results for selected target organs in 138 individuals occupationally exposed to TCDD. Chemosphere 29 : 2423-2437, 1994

62. Nagayama J, Tsuji H, lida T, Hirakawa H, Matsueda T, Ohki M : Effects of contamination level of dioxins and related chemicals on thyroid hormone and immune response systems in patients with "Yusho". Chemosphere 43 : 1005-1010, 2001

63. Pavuk M, Schecter AJ, Akhtar FZ, Michalek JE : Serum 2,3,7,8-tetrachlorodibenzo-p-dioxin (TCDD) levels and thyroid function in Air Force Veterans of the Vietnam War. Ann Epidemiol $13: 335-343,2003$

64. Koopman-Esseboom C, Morse DC, WeisglasKuperus N, Lutkeschipholt IJ, Van der Paauw CG, Tuinstra LGMT, Brouwer A, Sauer PJJ : Effects of dioxins and polychlorinated biphenyls on thyroid hormone status of pregnant women and their infants. Pediatr Res 36:468-473, 1994

65. Johnson ES, Shorter C, Bestervelt LL, Patterson DG, Needham LL, Piper WN, Lucier G, Nolan CJ :Serum hormone levels in humans with low serum concentrations of 2,3,7,8-TCDD. Toxicol Ind Health $17: 105-112,2001$

66. Nagayama J, Iida T, Hirakawa H, Matsueda T, Tsuji H, Okamura K, Hasegawa M, Sato K, Kitahara E, Ma H-Y, Yanagawa T, Igarashi H, Fukushige $\mathrm{J}$, Watanabe T: Effects of lactational exposure to chlorinated dioxins and related chemicals on lymphocyte subpopulations and thyroid functions in Japanese babies. Organohalogen Compounds $28: 228-233,1996$

67. Pluim HJ, de Vijlder JJM, Olie K, Kok JH, Vulsma T, van Tijn DA, van der Slikke JW, Koppe JG : Effects of pre-and postnatal exposure to chlorinated dioxins and furans on human neonatal thyroid hormone concentrations. Environ Health Perspect 101 : 504-508, 1993

68. Matsuura N, Uchiyama T, Tada H, Nakamura Y, Kondo N, Morita M, Fukushi M : Effects of di- 
oxins and polychlorinated biphenyls (PCBs) on thyroid function in infants born in Japan-the second report from research on environmental health. Chemosphere $45: 1167-1171,2001$

69. Schantz SL, Widholm JJ, Rice DC : Effects of PCB exposure on neuropsychological function in children. Environ Health Perspect 111:357376, 2003

70. Guo YL, Lambert GH, Hsu CC, Hsu ML:Yucheng : health effects of prenatal exposure to polychlorinated biphenyls and dibenzofurans. Int Arch Occup Environ Health 77 : 153-158, 2004

71. Kakeyama M, Tohyama C : Developmental neurotoxicity of dioxin and its related compounds. Ind Health $41: 214-230,2003$

72. Jacobson JL, Jacobson SW, Humphery HEB : Effects of in utero exposure to polychlorinated biphenyls and related contaminants on cognitive functioning in young children. J Pediatr 116 : 38-45, 1990

73. Stewart P, Reihman J, Lonky E, Darvill T, Pagano $\mathrm{J}$ : Prenatal PCB exposure and neonatal behavioral assessment scale (NBAS) performance. Neurotoxicol Teratol 22, 21-29, 2000

74. Grandjean P, Weihe P, Burse VW, Needham LL, Storr-Hansen E, Heinzow B, Debes F, Murata $\mathrm{K}$, Simonsen H, Ellefsen P, Budtz-Jorgensen E, Keiding N, White RF : Neurobehavioral deficits associated with PCB in 7-year-old children prenatally exposed to seafood neurotoxicants. Neurotoxicol Teratol 23 : 305-317, 2001

75. Rogan WJ, Gladen BC, McKinney JD, Carreras N, Hardy P, Thullen J, Tingelstad J, Tully M : Polychlorinated biphenyls (PCBs) and dichlorodiphenyl dichloroethene (DDE) in human milk: effects of maternal factors and previous lactation. Am J Public Health 76 : 172-177, 1986

76. Rogan WJ, Gladen BC, McKinney JD, Carreras $\mathrm{N}$, Hardy P, Thullen J, Tinglestad J, Tully M : Neonatal effects of transplacental exposure to PCBs and DDE. J Pediatr 109 : 335-341, 1986

77. Gladen BC, Rogan WJ, Hardy P, Thullen J, Tingelstad J, Tully M: Development after exposure to polychlorinated biphenyls and dichlorodiphenyl dichloroethene transplacentally and through human milk. J Pediatr 113 : 991-995, 1988

78. Rogan WJ, Gladen BC: PCBs, DDE, and child development at 18 and 24 months. Ann Epidemiol 1: 407-413, 1991
79. Patandin S, Koopman-Esseboom C, de Ridder MAJ, Weisglas-Kuperus N, Sauer PJJ : Effects of environmental exposure to polychlorinated biphenyls and dioxins on birth size and growth in Dutch children. Pediatr Res 44 : 538-545, 1998

80. Koopman-Esseboom C, Weisglas-Kuperus N, de Ridder MAJ, van der Paauw CG, Tuinstra LGMT, Sauer PJJ : Effects of polychlorinated biphenyl/ dioxin exposure and feeding type on infants' mental and psychomotor development. Pediatrics 97 : 700-706, 1996

81. Patandin S, Lanting CI, Mulder PGH, Boersma ER, Sauer PJJ, Weisglas-Kuperus N:Effects of environmental exposure to polychlorinated biphenyls and dioxins on cognitive abilities in Dutch children at 42 months of age. J Pediatr 134 : 33-41, 1999

82. Huisman M, Koopman-Esseboom C, Fidler V, Hadders-Algra M, van der Paauw CG, Tuinstra LGMT, Weisglas-Kuperus N, Sauer PJJ, Touwen BCL, Boersma ER: Perinatal exposure to polychlorinated biphenyls and dioxins and its effect on neonatal neurological development. Ear Hum Dev $41:$ 111-127, 1995a

83. Huisman M, Koopman-Esseboom C, Lanting CI, van der Paauw CG, Tuinstra LGMT, Fidler V, Weisglas-Kuperus N, Sauer PJJ, Boersma ER, Touwen BCL: Neurological condition in 18 month old children perinatally exposed to polychlorinated biphenyls and dioxins. Ear Hum Dev 43:165-176, 1995b

84. Lanting CI, Patandin S, Fidler V, Weisglas-Kuperus N, Sauer PJJ, Boersma ER, Touwen BCL : Neurological condition in 42-month-old children in relation to pre-and postnatal exposure to polychlorinated biphenyls and dioxins. Ear Hum Dev 50 : 283-292, 1998

85. Winneke G, Bucholski A, Heinzow B, Kramer U, Schmidt E, Walkowiak J, Wiener JA, Steingruber HJ : Developmental neurotoxicity of polychlorinated biphenyls (PCBs): cognitive and psychomotor functions in 7-month old children. Toxicol Lett 102-103 : 423-428, 1998

86. Walkowiak J, Wiener JA, Fastabend A, Heinzow B, Kramer U, Schmidt E, Steingruber HJ, Wundram S, Winneke : Environmental exposure to polychlorinated biphenyls and quality of the home environment :effects on psychodevelopment in early childhood. Lancet 358 : 1602-1607, 2001 